\title{
Oxidation Kinetics of High Strength Low Alloy Steels at Elevated Temperatures
}

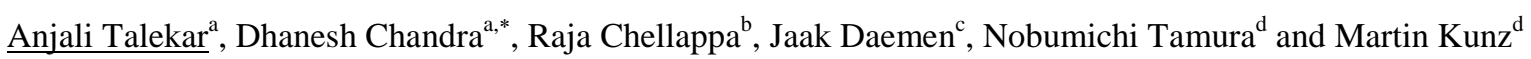

\author{
${ }^{\mathrm{a}}$ Materials Science and Engineering, \\ Chemical and Metallurgical Engineering Department, \\ University of Nevada, Reno, Reno, NV 89557 \\ ${ }^{\mathrm{b}}$ Geophysical Laboratory \\ Carnegie Institution of Washington \\ 5251 Broad Branch Road \\ Washington, DC 20015 \\ ${ }^{c}$ Mining Engineering Department, \\ University of Nevada, Reno, Reno, NV 89557 \\ ${ }^{\mathrm{d}}$ Advanced Light Source, \\ Lawrence Berkeley National Laboratories, \\ MS 2R0222, Berkeley, CA 94720
}

* Corresponding author. Tel: 1-775-784-4960; fax: 1-775-784-4316

E-mail address: dchandra@unr.edu (D. Chandra) 


\begin{abstract}
High Strength Low Alloy (HSLA) steels are candidate Rockbolt materials for use as underground roof supports at Yucca Mountain nuclear waste repository. Oxidation kinetics of International Rollforms Split Set Friction Rock Stabilizers (SS46), and Swellex Mn24 steels have been determined by temperature modulated thermogravimetry at temperatures ranging between $600{ }^{\circ} \mathrm{C}$ to $900{ }^{\circ} \mathrm{C}$ in pure oxygen atmosphere for $100 \mathrm{hr}$. The imposed sinusoidal temperature modulations on the isothermal temperature did not have any apparent effect on the weight gain characteristics during oxidation. Weight gain data on the steels indicate two distinct regions with different oxidation profiles, where a definite change in rates of oxidation is observed: a first oxidation regime where the steels followed a rate law $y=k \mathrm{t}^{0.40-0.63}$ (changing index of rate law depending upon steel and temperature) and a second stage oxidation regime that follows the parabolic law. The results of characterization of the oxide films using SEM/EDAX and X-ray diffraction are presented.
\end{abstract}

Keywords: C. High-temperature oxidation, ? thermogravimetry, C. Oxidation Kinetics, C. Activation Energy

\title{
1. Introduction
}

Metal or alloy deterioration occurs incessantly and conservation or reversal of the process forms the basis for a huge industry. Alloys in their various compositions are segregated for use in specialized applications based on the properties they are engineered to exhibit. High Strength Low Alloy (HSLA) structural steels are considered to be candidate materials for Rockbolts and other underground metallic roof supports (tunnel ribs, borehole liners or mesh etc.) in the Yucca Mountain Nuclear waste repository. Yucca Mountain located in Nye county, Nevada and about 100 miles Northwest of Las Vegas, Nevada was finalized as the nation's proposed repository for spent nuclear fuel in 1987 [1] under the direction of congress based on its various potential advantages. HSLA steels are microalloyed with specific alloying elements to increase the mechanical strength, enhance formability and weldability as well as providing greater oxidation resistance 
(and atmospheric corrosion) than low carbon steels [2]. The microalloying effect of various elements such as $\mathrm{C}, \mathrm{Si}, \mathrm{Mn}, \mathrm{Cu}$, and others on the corrosion resistance of steels (including stainless steels) have been discussed in standard texts [3-8]. Friction-type rock stabilizers [FRS] as rock reinforcement are needed to support underground construction and have been in use since the 1970's. Slotted and tapered [Split-sets] or collapsed $\left[\right.$ Swellex Mn-24 $\left.{ }^{\mathrm{TM}}\right]$ steel tube-type FRS are the most commonly used today. Split sets were introduced commercially in the 1997 [9]. A Split Set consists of two parts: tube and plate. The high-strength steel tube is slotted along its entire length. The tube is tapered at one end to facilitate easy insertion and the other end has a welded ring which holds the plate firmly. A slightly smaller hole is made in the rock-bed and the tube, with the bearing domed plate in place, is driven into it. As the Split Set is pushed into the smaller hole, its slot narrows, and the tube partially closes, simultaneously exerting radial pressure against the rock over its full contact length. The dome shape of the plate provides a stronger support to the tube as compared to a flat plate. The grip of the Split Sets increases over time with rock shifts and rock bursts as the yieldable tube confirms to the changing conditions while maintaining the holding force. The Swellex Mn-24 Rock bolt is made up of a double-folded thin-walled HSLA tube. The ends of the Rock Bolt are sealed by welding bushings at both the ends. A hole made in one of the bushings is used to pump in water at high pressure ( $30 \mathrm{MPa})$ to expand the bolt [10]. As the tube expands, it contours to the shape of the surrounding rock asperities and the hole. Later the water is drained and the tube stays in frictional anchorage with the bore hole via contact stresses and mechanical interlocking due to roughness of the borehole [10]. As the name suggests Mn stands for the added manganese as a strengthening agent and 24 stands for a typical breaking load of 24 tons (US) for a $3 \mathrm{~mm}$ tube.

The complex oxidation behaviour of iron and its alloys in air and pure oxygen is well known [11-17] Boggs et al. [17] reviewed the effects of metal composition, cold work, crystallographic orientation, etc on the oxidation process. They clearly showed that residual concentrations of impurities or additions like $\mathrm{Al}, \mathrm{Cr}, \mathrm{Si}$, which are less noble than iron tend to reduce oxide scale adherence thus altering oxidation characteristics. Uhlig [18] presented that oxidation rates are dependent upon crystal orientations, lattice transformations and Curie temperatures at the metal-oxide interface. Chen and Yuen [19] have also compared oxidation behaviours of commercial low carbon and ultra-low carbon steels at $700-950{ }^{\circ} \mathrm{C}$ in air showing the divergence 
of oxidation kinetics from know parabolic law at various temperatures. They provide instances of where the steels under study showed very low oxidation rates initially then the rates accelerated and subsequently decelerated with time. They have reported parabolic rate constants from "parabolic zones" and used the numerical values to compare the oxidation behaviour. Pieraggi [20] has shown the importance of using a square root plot for measuring parabolic rate constants as against to a square of weight-gain plot. Quadakkers [21] have shown the presence of a non-parabolic, transient region in the initial stages of oxidation for their Fe$\mathrm{Cr}$-Al alloy samples which after longer times is known to change into a stable scale growth obeying the parabolic law. Several authors [22-26] have elaborated on various mechanisms for oxidation governed by different rate laws in iron and its alloys and especially steels. Sachs and Jay [27, 28] have studied the decomposition of wustite $(\mathrm{FeO})$ during continuous cooling of different mild steel samples in a rolling mill. Their [27] concern was with the effect of cooling rates on the thickness and structure of the oxide scales formed on rolled wire rods. In a second paper [28] they examined the microstructural features of a magnetite layer found in adherent oxide scales on steels and give an explanation as to the origin of the layer and its contribution to the accelerated decomposition of the wustite layer. In a recent review, Chen and Yuen [29] have provided an overview of the oxidation behaviour of pure iron and carbon steels in air and oxygen. However, their focus was on summarizing the effect of carbon content on the oxidation behaviour of steel as compared to pure iron. Rather interestingly, there are only few studies that are devoted to determining the oxidation kinetics of structural steels in pure oxygen atmosphere at higher temperatures. Notably, Chang [30] compared the oxidation kinetics of five structural steels, a corrosion resistant ST2 steel, A36 (UNS K02600) general structural steel, A515 (UNS K02800) high temperature boiler and pressure vessel steel, A588 (UNS K11430) weather steel, and SM rolled steel for welded structure and determined that ST2 had the highest long term oxidation resistance (up to 18 days) in pure $\mathrm{O}_{2}$ atmosphere at $600{ }^{\circ} \mathrm{C}$. The composition of ST2 steel is given in Table I for comparison purposes with the steels used in this study. Abuluwefa et al. [26] determined the effect of oxygen concentration (up to $15 \%$ ) at higher temperatures from 1000 to $1250{ }^{\circ} \mathrm{C}$. Khanna et. al [31] illustrated the presence of an inversion phenomenon and breakaway oxidation for Cr-Mo steels with Si. They concluded that the phenomenon was not restricted to high Si steels and could occur as an effect of the atmosphere used for oxidation. 
The present study focuses on determination of high temperature oxidation kinetics of two HSLA steels: Split Set Rock Stabilizer designated as SS46 (46 refers to the tube diameter in mm) from International Rollforms, Inc. (certified as ASTM A607-98, Grade 50 after chemical analysis) and Swellex Mn24 from Atlas Copco., designated as AISI-SAE 1513 steel (UNS G15130) [32]. Table 1 below shows the chemical composition of the alloys used in this study. It can be seen that the main difference between SS46 and Mn24 is the increased Mn content in $\mathrm{Mn} 24$, and the presence of $\mathrm{Si}$ and $\mathrm{Al}$ in $\mathrm{Mn} 24$. The presence of $\mathrm{Cu}$ and very low levels of $\mathrm{Cr}$ are not expected to play any significant role in the oxidation behaviour of Mn24 although they increase the strength of the alloy [6]. It is also pointed out that the carbon content of $\sim 0.1$ wt $\%$ in both the steels is well below the carbon contents at which the steels undergo decarburization [29]. "Dry corrosion" or "scaling" as High temperature corrosion is often called, is evaluated by oxidation experiments with variables such as temperature, pressure, reaction atmosphere, etc. Reaction rates, morphology of reaction products, composition and changes occurring in the base metal, all provide an insight into the oxidation mechanisms [4].

\subsection{Oxidation Kinetics}

The oxidation behaviour of metals and alloys have been elucidated in many texts [2-4] as mentioned above; however a brief summary of the kinetic equations involved and the procedure for determining oxidation kinetics used in this study are given in this section. In principle, both isothermal and non-isothermal kinetics given by reaction rate, $(r)$ can be written as follows [33, 34]:

$r=\frac{d \alpha}{d t}=k(T) \cdot f(\alpha)$

where, $\alpha$ is the extent of reaction, $t$ is the time, and $k(T)$ is the temperature dependent rate constant (a constant value for isothermal experiments). The rate constant follows an Arrhenius relation given by: 
$k=k_{0} \exp \left(\frac{-\Delta E_{a}}{R \cdot T}\right)$

where $k_{0}$ is the pre-exponential factor (the intercept), $R$ is the gas constant, $T$ is the absolute temperature and $\Delta \mathrm{E}_{\mathrm{a}}$ is the activation energy. The activation energy is determined from the slope of $\ln k$ versus $1 / T$ plot. It is suffice to say that the oxidation kinetics of a metal or alloy is dependent on the nature of the oxide (including its semi-conducting properties, adherence to the substrate, volatility, diffusivity etc.) formed, the specimen preparation with uniform surface finish, and the oxidizing environment (pure $\mathrm{O}_{2}$, air, or some simulated environment such as kiln atmosphere). The weight gain (typically normalized with surface area and given as $\mathrm{mg} . \mathrm{cm}^{-2}$ ) as a function of time can follow a linear, parabolic, logarithmic or cubic relationship and such behaviour has been compiled for various metals and alloys [2]. In general, the rate law for oxidation kinetics can be given by:

$y=\left(\frac{W}{A}\right)=k t^{n}$

where, (W/A) is the weight gain per unit area at time $t, k$ is the rate constant and $n$ is the time exponent of the rate law.

\section{Experimental}

Oxidation weight gain experiments were conducted in a pure oxygen atmosphere using a commercial state-of-the-art thermogravimetric analyzer [35] at University of Nevada, Reno (TA Q500). It is equipped with a continuous weighing capacity of $1.0 \mathrm{~g}$, sensitivity of $0.1 \mu \mathrm{g}$, can handle heating rates from 0.1 to 50 ${ }^{\circ} \mathrm{C} \cdot \mathrm{min}^{-1}$ and has the ability to perform temperature Modulated TGA (MTGA). The weight gain as a function of time was recorded for HSLA steel specimens using data acquisition software provided with the instrument. The data acquisition allows recording of weight gain, modulated weight gain, temperature and modulated temperature continuously as a function of time. The mass calibration of TA Q500 was performed electronically by comparing with a known mass-set and the four point temperature calibration was performed by determining the curie transition temperature of $\mathrm{Ni}$, Alumel, and two Ni-Co alloys. 
Specimens of nominal dimensions $2 \mathrm{~mm} \times 3 \mathrm{~mm} \times 5 \mathrm{~mm}$ were polished successively on emery papers of grit size 240, 400, 600 and then fine polished with alumina paste of $1 \mu \mathrm{m}$ and $0.05 \mu \mathrm{m}$. The specimens were then cleaned ultrasonically and degreased with ethyl alcohol. The samples were placed in tared $500 \mu \mathrm{L}$ alumina pans and equilibrated (at a much higher heating rate) to the temperatures of interest $\left(600{ }^{\circ} \mathrm{C}\right.$ to $900{ }^{\circ} \mathrm{C}$ ). The sample chamber (tube furnace) was purged with ultra-high purity (UHP) oxygen at $90 \mathrm{~mL} \cdot \mathrm{min}^{-1}$ and a flow of ultra-high purity argon at $10 \mathrm{~mL} \cdot \mathrm{min}^{-1}$ was maintained in the balance chamber by means of a high precision Mass Flow controller (MFC). The test specimens were held isothermally at a set temperature for $100 \mathrm{hr}$ periods. A sinusoidal modulation of amplitude $\pm 5{ }^{\circ} \mathrm{C}$ was imposed for a period of 1 cycle per 200 seconds. This sinusoidal modulation creates an artificial perturbation around the mean isothermal temperature. The weight gain of the sample, temperature, and other data signals from the instrument were recorded every 30 seconds.

Analyses on raw weight gain data as a function of time were performed to determine the kinetic parameters. It was assumed that the dimensional changes (for the purpose of determining oxidation kinetics) to the test specimen before and after oxidation were negligible. Data after the specimens reached the temperature(s) of interest were used for kinetic measurements and any weight gain that may have occurred during the ramping period was neglected. The oxides formed were ground and powder XRD was performed to identify the species and phase composition. The oxide morphology was characterized using SEM and EDAX was also performed to determine the oxide composition. Synchrotron x-ray microdiffraction measurements were also performed on BL 12.3.2 at the Advanced Light Source, Lawrence Berkeley National Laboratory to supplement the SEM results.

\section{Results and Discussion}

Long term oxidation studies were carried out on two HSLA steels, Mn-24 and SS46, under pure oxygen atmospheres ad at different holding temperatures for $100 \mathrm{hrs}$. The weight gain versus time plots for these 
alloys are given in Figures 1 and 2 respectively. Although data were collected every 30 seconds, the figures show data for every 2 hours for clarity.

As seen from Figure 1 oxidation rates are seen to increase with temperature. Oxidation kinetics at all temperatures (except at $600{ }^{\circ} \mathrm{C}$ ) show a period of fast and linear oxidation followed by a sluggish phase. At $750^{\circ} \mathrm{C}$, the kinetics is slower than those at $675^{\circ} \mathrm{C}$ after about 22 hours. Oxidation kinetics at $775{ }^{\circ} \mathrm{C}$ initially follows the $750^{\circ} \mathrm{C}$ kinetics closely and then is higher than the lower temperature as expected. At 825 and $900{ }^{\circ} \mathrm{C}$, the oxidation kinetics are very fast right from the starting as compared to those observed at other temperatures and undergo breakaway oxidation after only a few hours of oxidation. At $900{ }^{\circ} \mathrm{C}$ breakaway oxidation is observed after about 30 hours and at $825{ }^{\circ} \mathrm{C}$ it is observed after about 32 hours. Although oxidation kinetics at $600{ }^{\circ} \mathrm{C}$ looks constantly increasing in Fig.1, there is definite spalling of the oxide layer observed after about 37 hours on an expanded scale. Plotting square of weight gain data per unit area vs. square root of time shows a strong change in slope at points where a break in protective oxide film is encountered.

For SS-46 (Figure 2) oxidation rates show a consistent increase with increasing temperature. Oxidation rates at 600 and $675{ }^{\circ} \mathrm{C}$ are slow initially up to about 22 hours as compared to the oxidation rates at temperatures from 750 to $900{ }^{\circ} \mathrm{C}$. Breakaway oxidation is observed for $900{ }^{\circ} \mathrm{C}$ after only about 5.5 hours. Changes in slopes indicating oxide spalling are observed for $775{ }^{\circ} \mathrm{C}$ at $\sim 83.19$ hours, for $800{ }^{\circ} \mathrm{C}$ at $\sim 50.56$ hours and for $825^{\circ} \mathrm{C}$ at about 39 hours.

The experiments in this study were carried out by superposing a known irregularity in the temperature regime to create an isothermal temperature profile with a sinusoidal time varying perturbation. Such a perturbation can also be interpreted as a structured uncertainty in the desired temperature. A typical modulated temperature superimposed with the average isothermal temperature and weight percent gain for the SS46 sample $\left(\mathrm{T}=750{ }^{\circ} \mathrm{C}\right)$ is shown in the inset in figure-2. Model free calculation of activation energies based on modulated weight gains observed are found in references [36-38]. It is seen though, that activation energy calculation using the model free technique is quite dependent on the localized weight changes 
occurring in the small time period of modulations. The period of modulations chosen in all our experiments was only 200 seconds whereas the total duration of one experiment was 100 hours. It is expected that temperature modulated thermogravimetry will be more relevant when conducting nonisothermal ramping experiments since the weight gain curves (depending upon the material) would display noticeable changes even with short time periods. Such an effect will be more pronounced depending upon the heating rate as well. For example, the oxidation curves of pure iron reported by Roy et al. [39] in their nonisothermal experiments reveal a steep slope of the weight gain per unit area. Therefore, in this study, we only emphasize the calculation of activation energy as well as oxidation kinetic parameters based on the traditional analysis. For the oxidation kinetics studies conducted for SS46 and Mn24 in this study, the oxidation regimes were typically divided into three parts: (1) initial stage oxidation region (that can be considered as incubation period for lower temperature but it is linear-type for higher temperature) (2) a first oxidation regime (time exponent of rate law varying from 0.40 to 0.63 , depending upon material and temperature), and (3) a second oxidation regime following parabolic-type oxidation for longer oxidation time. A transient portion is observed between each of the regimes where the kinetics undergoes transition from one regime to another. A plot of log $\left(\mathrm{y} / \mathrm{kg} \cdot \mathrm{m}^{-2} \cdot \mathrm{s}^{-1}\right)$ versus $\log (\mathrm{t} / \mathrm{s})$ is shown in figure 3 for $\mathrm{Mn} 24$ at $800{ }^{\circ} \mathrm{C}$. It is visually clear that during the initial stages of oxidation, the slope of d $(\log \mathrm{y}) / \mathrm{d}(\log \mathrm{t})$ is relatively small. For SS46 it is $0.009\left(600{ }^{\circ} \mathrm{C}\right), 0.014$ $\left(675{ }^{\circ} \mathrm{C}\right), 0.017\left(750{ }^{\circ} \mathrm{C}\right), 0.074\left(775{ }^{\circ} \mathrm{C}\right), 0.041\left(800{ }^{\circ} \mathrm{C}\right), 0.045\left(825{ }^{\circ} \mathrm{C}\right)$, and $0.015\left(900{ }^{\circ} \mathrm{C}\right)$ whereas for Mn24 it is $0.007\left(600{ }^{\circ} \mathrm{C}\right), 0.023\left(675^{\circ} \mathrm{C}\right), 0.03\left(750{ }^{\circ} \mathrm{C}\right), 0.071\left(775^{\circ} \mathrm{C}\right), 0.053\left(800{ }^{\circ} \mathrm{C}\right), 0.026\left(825^{\circ} \mathrm{C}\right)$, and $0.033\left(900{ }^{\circ} \mathrm{C}\right)$. For the first oxidation regime, a rate law was determined for SS46 and Mn24 which confirmed to the general form of equation (3). For SS46, the index of rate law varies from $\sim 0.40$ to $\sim 0.65$. For Mn24, it varies from $\sim 0.43$ to $\sim 0.63$. A plot of $\log y$ versus $\log t$ for determining kinetic parameters based on the regression data is shown in figure 4 for $\mathrm{Mn} 24$ at $800{ }^{\circ} \mathrm{C}$ and the values for rate constant and index of rate law for SS46 and Mn24 at 600, 675, 750, 775, 825, and $900{ }^{\circ} \mathrm{C}$ for both the materials are compiled in Table II. The fit of the linear regression for all the curves was found to lie between 0.98 to 0.99 . It is obvious from Table II that the units of $k$ are not consistent for plotting $\ln k$ versus $1 / \mathrm{T}$ to determine the activation energy for this first oxidation regime. Therefore, for the purpose of determining activation energy the index of rate law is assumed to be 0.52 for SS46 and Mn24. A plot of $y$ versus $\mathrm{t}^{0.52}$ is used to determine the rate 
constant. The determined rate constants were then used in a plot of $\ln k$ versus 1/T (Figure 5 for Mn24 and Figure 6 for SS46) and the activation energies were calculated and are also tabulated in Table II. The activation energy for SS46 is $101.6 \mathrm{~kJ}$ and for Mn24 it is $\sim 82.27 \mathrm{~kJ}$ for the first oxidation region.

Longer oxidation periods (up to $100 \mathrm{hrs)} \mathrm{showed} \mathrm{the} \mathrm{oxidation} \mathrm{kinetics} \mathrm{to} \mathrm{follow} \mathrm{parabolic} \mathrm{oxidation} \mathrm{for}$ SS46 as well as Mn24. For SS46, parabolic regimes started at: $\sim 52.36 \mathrm{hrs}\left(600{ }^{\circ} \mathrm{C}\right), \sim 65.7 \mathrm{hrs}\left(675{ }^{\circ} \mathrm{C}\right), \sim 22$ hrs $\left(750^{\circ} \mathrm{C}\right), \sim 13 \mathrm{hrs}\left(775^{\circ} \mathrm{C}\right), \sim 65 \mathrm{hrs}\left(800^{\circ} \mathrm{C}\right), \sim 68 \mathrm{hrs}\left(825^{\circ} \mathrm{C}\right)$, and $\sim 66.5 \mathrm{hrs}\left(900{ }^{\circ} \mathrm{C}\right)$; whereas for Mn24 the regimes started at: $\sim 20.5 \mathrm{hrs}\left(600{ }^{\circ} \mathrm{C}\right), \sim 61 \mathrm{hrs}\left(675^{\circ} \mathrm{C}\right), 19.5 \mathrm{hrs}\left(750{ }^{\circ} \mathrm{C}\right), \sim 34.5 \mathrm{hrs}\left(775{ }^{\circ} \mathrm{C}\right), \sim 45.8 \mathrm{hrs}$ $\left(800{ }^{\circ} \mathrm{C}\right), \sim 50.6 \mathrm{hrs}\left(825{ }^{\circ} \mathrm{C}\right)$, and $\sim 50 \mathrm{hrs}\left(900{ }^{\circ} \mathrm{C}\right)$. Slope of a plot of $y$ versus root $t$ gives the values for the rate constants in the parabolic regime for SS46 and Mn24. It has been shown by Pieraggi et. al. [20] that "a plot of kinetics data as $\Delta \mathrm{m}$ versus $\mathrm{t}^{1 / 2}$ is inherently superior to $\Delta \mathrm{m}^{2}$ versus $\mathrm{t}$ plot for accurate determination of steady state parabolic rate constant". It has been shown by numerous researchers $[18,30,31,40,41]$ that metals and alloys demonstrate oxidation rate laws that deviate from the classic Linear, Parabolic or Logarithmic rate equations. Sometimes a combination of these rate laws is also observed for a material over a period of oxidation times. Most of the times a period of transient faster kinetics is initially observed, succeeded by the steady state parabolic law. When the initial weight gain $\Delta \mathrm{m}_{\mathrm{i}}$ does not contribute to steady state rate control because of initial growth of poorly protective oxide scale, Pieraggi [20] suggests using a plot of $\Delta m$ versus $t^{1 / 2}$ for evaluation. He clearly demonstrated that the use of a $\Delta m^{2}$ versus $t$ plot for analyses does not allow for the determination of the true parabolic constant $k_{p}$ nor the transient weight $\Delta m_{i}$. A combined plot of $\Delta m$ versus $t^{1 / 2}$ for SS46 and Mn24 is shown in Figure 7 for comparison and shows the value of $k p=9.99 \mathrm{x}$ $10^{-9} \mathrm{~kg}^{2} \cdot \mathrm{m}^{-4} \mathrm{~s}^{-1}$ for SS46 at $750{ }^{\circ} \mathrm{C}$ is an order of magnitude higher than that for Mn24 which is $k p=1.717 \mathrm{x}$ $10^{-10} \mathrm{~kg}^{2} \cdot \mathrm{m}^{-4} \mathrm{~s}^{-1}$ suggesting that the long term oxidation resistance of $\mathrm{Mn} 24$ at $750{ }^{\circ} \mathrm{C}$ is better than that of SS46. However overall comparison of $k_{p}$ values at different temperatures shows no definite suggestion of a better oxidation resistance of one material over the other since the values are very erratic (Figure 8). Although the linear regression fit to the parabolic rate constants is extremely low, based on calculated values, activation energy of Swellex Mn24 was $\sim 81.68 \mathrm{~kJ}$ and that for SS46 was found to be $\sim 83 \mathrm{~kJ}$. 
Both the steels in this study are low carbon, low alloy steels. The carbon content of the steels $\sim 0.1 \mathrm{wt} \%$ is well below the carbon contents that steels undergo decarburization [29]. Morphology of the oxides formed on the SS46 and Mn24 steels was studied under Scanning Electron Microscope and Figures 9and 10 show the micrographs for SS46 and Mn24 respectively at 600 and $800{ }^{\circ} \mathrm{C}$. At $600^{\circ} \mathrm{C}$, both steels showed uniform grains all over the surface. A single layered smooth oxide scale was observed on the steels. The oxide layer on Mn24 showed greater porosity as compared to that seen in the SS46 oxide. Figure 9(a) and 10(a) show the oxides formed on SS46 and Mn24 respectively at $600^{\circ} \mathrm{C}$. The thickness of the oxide layer varied from $33 \mu \mathrm{m}$ to $\sim 45 \mu \mathrm{m}$ for the SS46 sample at $600^{\circ} \mathrm{C}$ whereas the oxide layer on $\mathrm{Mn} 24$ was $\sim 95.7 \mu \mathrm{m}$ at its thinnest and $\sim 145 \mu \mathrm{m}$ at its thickest after 100 hours of isothermal oxic holding. The oxide layer on Mn24 seemed to be partially detached from the base alloy. The nominal composition of the oxide layer on $\mathrm{Mn} 24$ at $600^{\circ} \mathrm{C}$ is $\mathrm{Fe}$ $(75.73 \mathrm{wt} \%, 47.60$ at $\%)$ and $\mathrm{O}(23.73 \mathrm{wt} \%, 52.05$ at $\%)$ showing that the oxide is primarily composed of hematite and some retained wustite. Scale structures found on steels vary considerably from the wellestablished scale structures that form on pure iron [25, 42-44]. Although pure iron sports a three layered oxide structure with wustite being the thickest innermost layer, under normal pressure $\mathrm{Fe}_{1-\mathrm{x}} \mathrm{O}$ is metastable below $570{ }^{\circ} \mathrm{C}(\sim 843 \mathrm{~K})$ and decomposes to metallic iron and magnetite [45]. It has not been reported to be a predominant oxide layer during long term oxidation [46]. For Mn24 oxidized at $675{ }^{\circ} \mathrm{C}$, the oxide was separated from the base alloy and lager grains were observed in the interior of the alloy as compared to the ones found near the oxide layer (not shown). The nominal composition of the oxide layer on Mn24 oxidized at $675^{\circ} \mathrm{C}$ is $\mathrm{Fe}(72.76 \mathrm{wt} \%, 44.06$ at \%) and $\mathrm{O}(26.14 \mathrm{wt} \%, 55.26$ at \%) suggesting a mixture of hematite and wustite. The oxide layer on SS46 oxidized at $675^{\circ} \mathrm{C}$ disintegrated when the sample was taken out of the sample pan after the experiment. The base alloy seemed to be intact but the oxide broke. EDAX results suggest the presence of a mixture of hematite and magnetite. The nominal compositions of the metal oxide interface for SS46 oxidized at $750{ }^{\circ} \mathrm{C}$ is $\mathrm{Fe}(78.99 \mathrm{wt} \%, 52.3$ at\%), O (20.49 wt\%, 47.35 at\%), and Mn (0.52 $\mathrm{wt} \%, 0.35$ at $\%$ ). The 100-hour SS46 sample seemed to stick to the sample pan and when it was pulled out; the oxide layer broke from the substrate but did not disintegrate. For Mn24 oxidized at $800{ }^{\circ} \mathrm{C}$ three distinct layers are observed, innermost layer of wustite $(\mathrm{FeO})$, an intermediate layer of magnetite $\left(\mathrm{Fe}_{3} \mathrm{O}_{4}\right)$ and the outermost layer rich in oxygen of hematite $\left(\mathrm{Fe}_{2} \mathrm{O}_{3}\right)$. Chen and Yuen [29] have described the formation of 
blisters and different layered scale structures very well. Stresses due to different diffusion coefficients of iron and oxygen, different thermal expansion coefficients of the oxide scale and the substrate and the plasticity of the oxide scale are factors causing blistering of the scale. Once the scale detaches from the base alloy, the iron rich wustite formed near the substrate is oxidized to higher oxides after long term oxidation [29, 42, 44]. The pseudomorphic conversion of wustite to hematite is also thermodynamically favoured involving internal atomic arrangements in the dry state [46]. The process usually takes place at higher temperatures. The presence of a thin layer of wustite is also a result of the very slow cooling rate of the samples [47]. The approximate thickness of the layers measured on $\mathrm{Mn} 24$ oxidized at $800{ }^{\circ} \mathrm{C}$ was: $\mathrm{FeO}-30.4 \mu \mathrm{m}, \mathrm{Fe}_{3} \mathrm{O}_{4}-$ $106 \mu \mathrm{m}, \mathrm{Fe}_{2} \mathrm{O}_{3}$ —varied between 160 to $167 \mu \mathrm{m}$. For SS-46 oxidized at $800{ }^{\circ} \mathrm{C}$, the micrograph shows a thin layer of magnetite separated from the wustite layer. Wustite is not reported as a predominant layer during steel oxidation in literature but our studies on SS46 at $800{ }^{\circ} \mathrm{C}$ indicate otherwise. This can be confirmed only after performing a depth-profile analysis of the oxidized sample. The wustite layer on SS46 was $\sim 35.4 \mu \mathrm{m}$ and the hematite layer was $\sim 130 \mu \mathrm{m}$ in thickness. The presence of the aforesaid oxide layers was confirmed with Synchrotron white beam x-ray microdiffraction, the results for which are shown in figures 9 and 10 respectively for SS46 and Mn24. The sample was scanned under a 1 um size polychromatic beam with a 2.5 um step size and a Laue diffraction pattern has been collected at each step and indexed for phase identification. In both samples, the presence of hematite and wustite was confirmed but no diffraction pattern could be obtained from the layers identified as magnetite by EDAX, indicating that this latter oxide formed with a very fine nanometer size grain structure compared to the micrometric size of the wustite and hematite grains.

\section{Conclusions}

1. The high temperature oxidation kinetics of International Rollforms Split Set Friction Rock Stabilizers (SS46) and Swellex Mn24 steels have been determined at $600{ }^{\circ} \mathrm{C}, 675{ }^{\circ} \mathrm{C}, 750{ }^{\circ} \mathrm{C}, 775{ }^{\circ} \mathrm{C}, 800{ }^{\circ} \mathrm{C}, 825$ ${ }^{\circ} \mathrm{C}$, and $900{ }^{\circ} \mathrm{C}$ for a period of $100 \mathrm{hr}$. oxidation To the best of our knowledge, this is the first reported study on the oxidation kinetics of these steels. 
2. The analysis of the oxidation weight gain curves of both SS46 and Mn24 show that there are three distinct oxidation regions: an incubation period; a first oxidation region, where the steels follow a rate law given by $y\left(k g \cdot \mathrm{m}^{-2}\right)=k t^{0.43-0.62}$ and a parabolic oxidation regime thereafter.

3. The rate constants determined for the first oxidation region for the steels show that the activation energies of both the HSLA steels is comparable at $82.27 \mathrm{~kJ}$ for Mn24 and $101.6 \mathrm{~kJ}$ for SS46. Activation energy was calculated assuming an average time exponent of the rate law of 0.52 for SS46 and Mn24.

4. Parabolic rate constants for both the steels show considerable scatter on an Arrhenius plot. Activation energies of $\sim 81.68 \mathrm{~kJ}$ for Swellex Mn24 and $\sim 83 \mathrm{~kJ}$ for SS46 were determined based on calculated parabolic rate constants. The scatter on the rate constants is attributed to the observed blistering of oxide scales and breakaway oxidation. Similar discrepancies have been observed by Jha et. al. [40] during oxidation studies in low alloy steels oxidized under high pressure oxidative environment from 700 to $1000{ }^{\circ} \mathrm{C}$ for oxidation times between 10 to 250 hours.

5. The SEM/EDAX of the metal oxide interface at lower temperatures show the presence of a thick hematite layer with possibly some wustite, whereas at higher temperatures three distinct oxides of iron can be identified in the scale. The presence of wustite has been confirmed by performing synchrotron microdiffraction. Also, the powder x-ray diffraction of the oxide layer at $900{ }^{\circ} \mathrm{C}(9 \mathrm{hr}$ oxidation times) also showed the presence of wustite in noticeable fraction although the pattern was predominantly hematite and magnetite (figure 11).

\section{Acknowledgements}


The authors wish to thank the Office of Civil Radioactive Waste management, of the U.S. Department of Energy (DOE) for funding this project under the cooperative agreement with the Nevada System of Higher Education (NSHE). (DOE-UCCSN Cooperative Agreement No.DE-FC-28-03RW12232). The Advanced Light Source (ALS) is supported by the Director, Office of Science, Office of Basic Energy Sciences, of the U.S. Department of Energy under Contract No. DE-AC02-05CH11231 at the Ernest Orlando Lawrence Berkeley National Laboratory (LBNL).

\section{References}

1. http://www.ocrwm.doe.gov/ym_repository/index.shtml

2. A.S. Khanna, High temperature oxidation and corrosion, 2002, Ohio: ASM International

3. O. Kubaschewski and B.E. Hopkins, Oxidation of metals and alloys, 1962, 2nd edition, New York: Academic Press Inc.

4. P. Kofstad, High temperature corrosion, 1988, New York: Elsevier Applied Science Publishers Ltd.

5. Steel-rolling technology: theory and practice / Vladimir B. Ginzburg.

6. High-strength, low-alloy steels: status, selection, and physical metallurgy / E. E. Fletcher

7. Alloying elements in steel, by Edgar C. Bain and Harold W. Paxton

8. Avner, Sidney H.: Introduction to Physical Metallurgy, McGraw-Hill, inc. ASM, Metals Handbook

9. Split set manual, Personal communication with Swellex Technical representative

10. C. Li and U. Håkansson, Rock Support and Reinforcement Practice in Mining, 1999, 103-108

11. N. B. Pilling and R. E. Bedworth, J. Inst. Met. 29, 529-591 (1923).

12. L. B. Pfeil, J. Iron Steel Inst. 119, 501-560 (1929).

13. K. Sachs and C. W. Tuck, Werkstoffe und Korrosion. Materials and Corrosion, 1970, 21 (11), p.945-954

14. J. Pai"dassi, Reû. Me'tall. 8, 569-585 (1957).

15. M. H. Davies, M. T. Simnad, and C. E. Birchenall, Trans. AIME 191, 889-896 (1951). 
16. J. Baud, A. Ferrier, J. Manenc, Oxidation of metals, 1978, 12(4), 331-342]. Boggs et al.

17. W.E. Boggs, High temperature gas-metal reactions in mixed environments; proceedings of the symposium, 1973, 84-128

18. H.H. Uhlig, Acta Metallurgica, 1956, 4, Sept., p. 541.

19. R.Y. Chen and W.Y.D. Yuen, Materials Science Forum, 2006, 522-523, p.451

20. B. Pieraggi, Oxidation of Metals, 1987, 27(3/4), Apr., p. 177

21. W.J. Quadakkers, D. Naumenko, E. Wessel, V. Kochubey and L. Singheiser, Oxidation of Metals, 2004, 61(1/2), Feb., p.17

22. Mott, Trans. Faraday Soc., 1940, 35, 472,

23. W.E. Boggs and R.H. Kachik, J. Electochem. Soc., 1969, 116 (4), p.424,

24. D.L. Carpenter and A.C. Ray, Corrosion Science (1973), 13(6), p. 493,

25. R. Y. Chen and W. D. Yuen, Oxidation of Metals, 2002, 57(1/2), Feb., p. 53,

26. H.T. Abuluwefa, R.I.L. Guthrie, and F. Ajersch, Oxidation of Metals, 1996, 46 (5/6), p.423.

27. K. Sachs, G. T. F. Jay, J. of the Iron and steel Inst., London, 1959, 193, 34-44

28. K. Sachs, G. T. F. Jay, J. of the Iron and steel Inst., London, 1960. 195, 180-189

29. R.Y. Chen and W.Y.D. Yuen, Oxidation of Metals, 2003, 59(5/6), June, p.433

30. Y.N. Chang., Corrosion, 1994, 50 (1), p.3.

31. A.S. Khanna, P. Rodriguez and J.B. Gnanamoorthy, Oxidation of Metals, 1986, 26(3/4), Oct., p. 171

32. J. L. Dossett and H. E. Boyer, "Practical Heat Treating $-2^{\text {nd }}$ Ed. " ASM International, 2006, Materials Park, Ohio.

33. S.K. Roy, A. Auddy, and S.K.Bose, Reactivity of Solids, 1989, 6, p.301.

34. T.P. Bagchi and P.K. Sen, Thermochim. Acta, 1981, 51, p.175.

35. www.tainst.com

36. R. Blaine, American Laboratory, 1998, 1, p.21.,

37. V. Mamleev, and S. Bourbigot, J. Therm. Anal. Cal., 2002, 70, p.565.,

38. S. Vyazovkin, and C. A. Wright, Thermochim. Acta.,1999, 340-341, p.53

39. S.K. Roy, A. Auddy, and S.K. Bose, Reactivity of Solids, 1989, 6, p.301 
40. R. Jha, C.W. Haworth and B.B. Argent, Calphad, 25(4), 2001, pp. 667,

41. K. Heindlhofer and B.M. Larsen, Trans. Of the A.S.S.T., 21 (1993) 865-98

42. K. Sachs and C. W. Tuck, Reheating for Hot Working (The Iron and Steel Institute, London, 1968), pp. $1-17$.

43. F. Matsuno, Trans. Iron Steel Inst. Jpn. 20, 413 (1980).,

44. C. W. Tuck, M. Odgers, and K. Sachs, Corros. Sci. 9, 271 (1969).

45. A.V. Palnichenko, A.N. Rossolenko, V.N. Kopylov, I.I. Zver'kova and A.S. Aronin, Chem. Phys. Letters, 410, 2-6 (2005), pp. 436

46. H.A. Wriedt, Binary Alloy Phase Diagrams, 1990, 2nd edition, vol.2. T.B. Massalski, H. Okamoto, P.R. Subramanian, and L. Kacprzak, eds (ASM Intern. OH)

47. R.Y. Chen and W.Y.D Yuen, ISIJ International, Vol. 45 (2005), No. 1, pp. 52-59. 


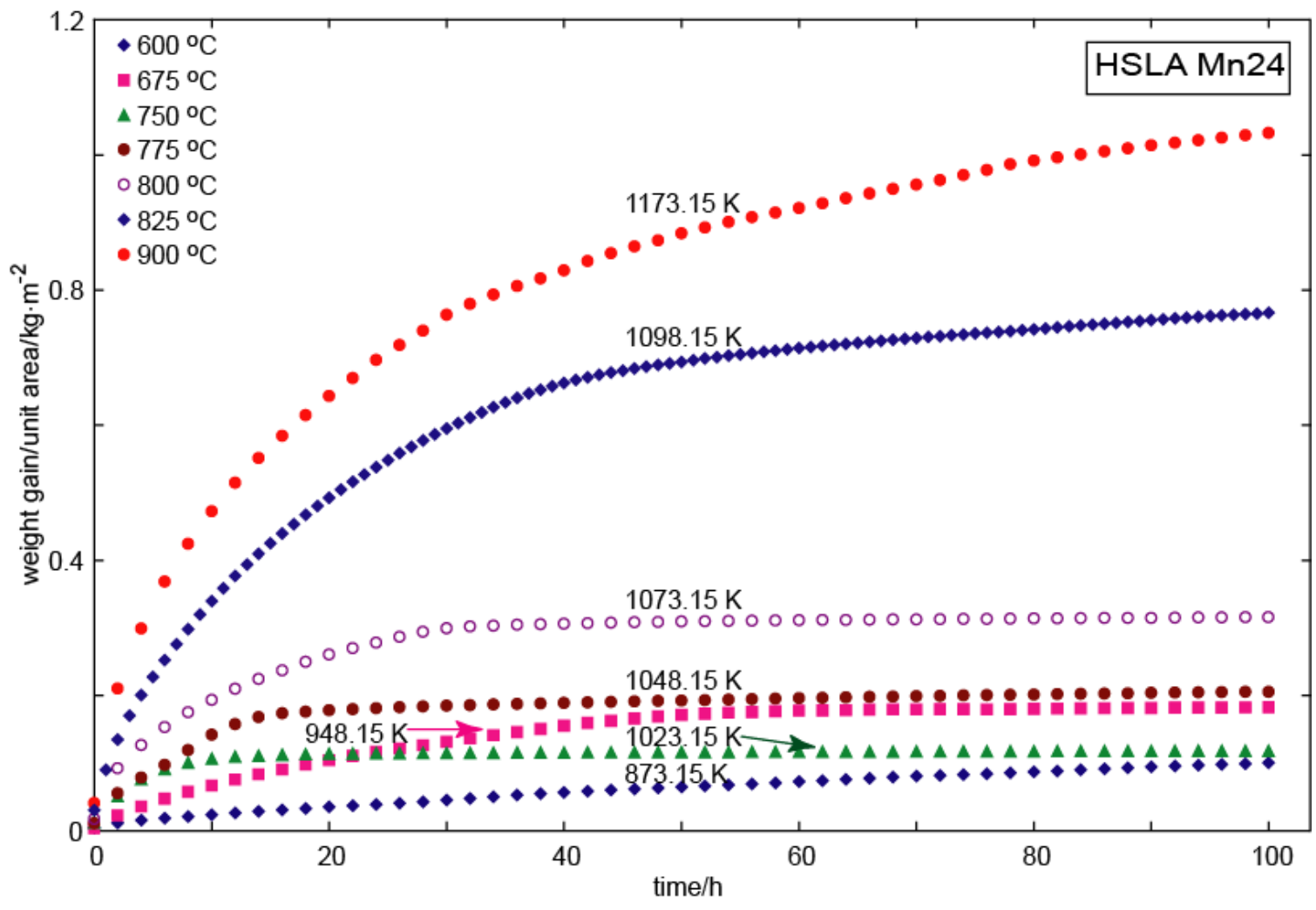

Figure 1 Weight gain per unit surface area versus time plot of Mn-24 at 600, 675, 750, 775, 800, 825, and 900 ${ }^{\circ} \mathrm{C}$ (y = weight gain/unit surface area). 


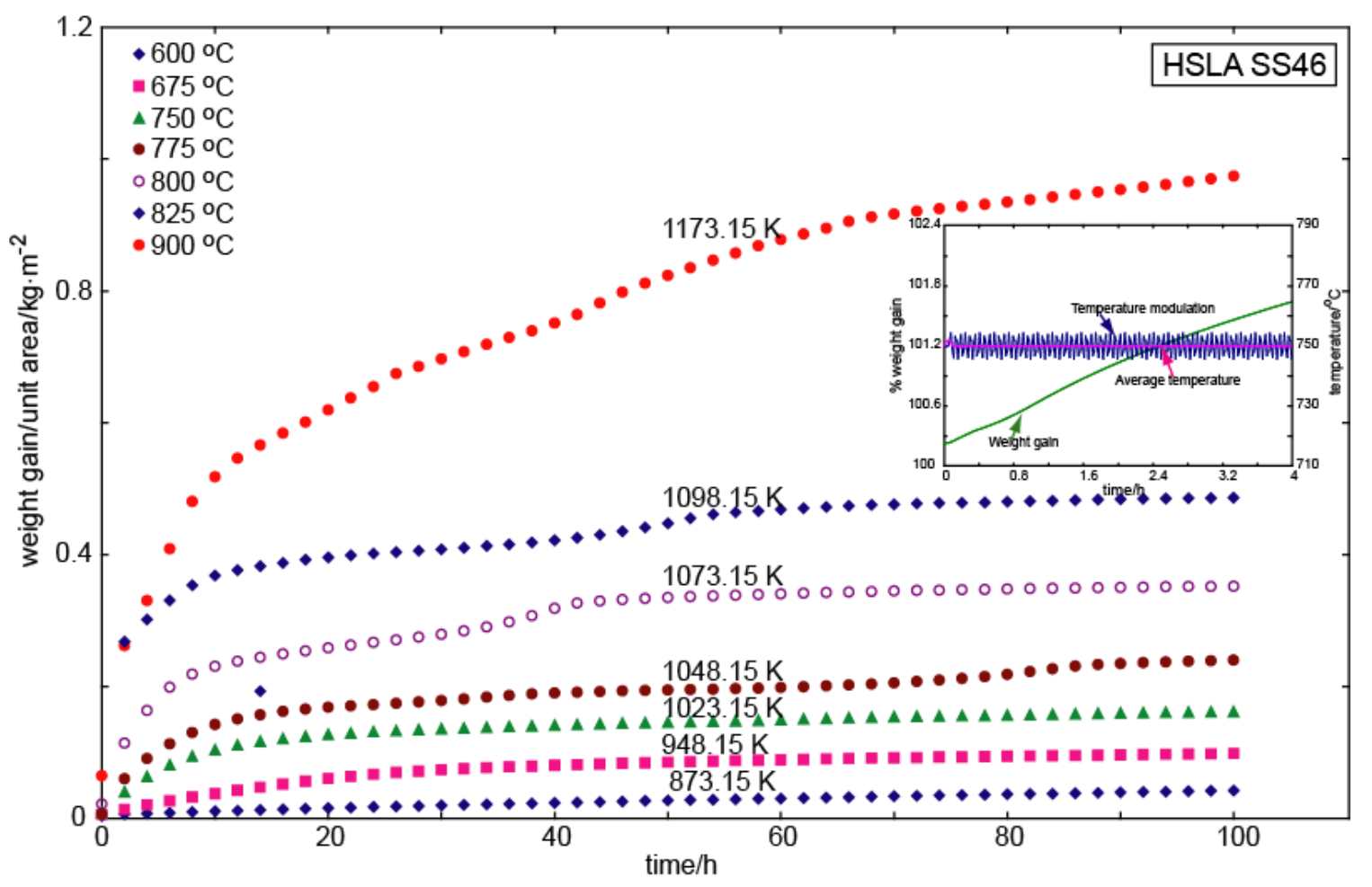

Figure 2. Weight gain per unit surface area versus time plot of SS-46 at 600, 675, 750, 775, 800, 825, and 900 ${ }^{\circ} \mathrm{C}$ (y= weight gain/unit surface area). Inset shows partial data (upto $4 \mathrm{hrs}$.) for average and modulated temperatures superimposed with the weight gain curve for SS46 at $750{ }^{\circ} \mathrm{C}$. 


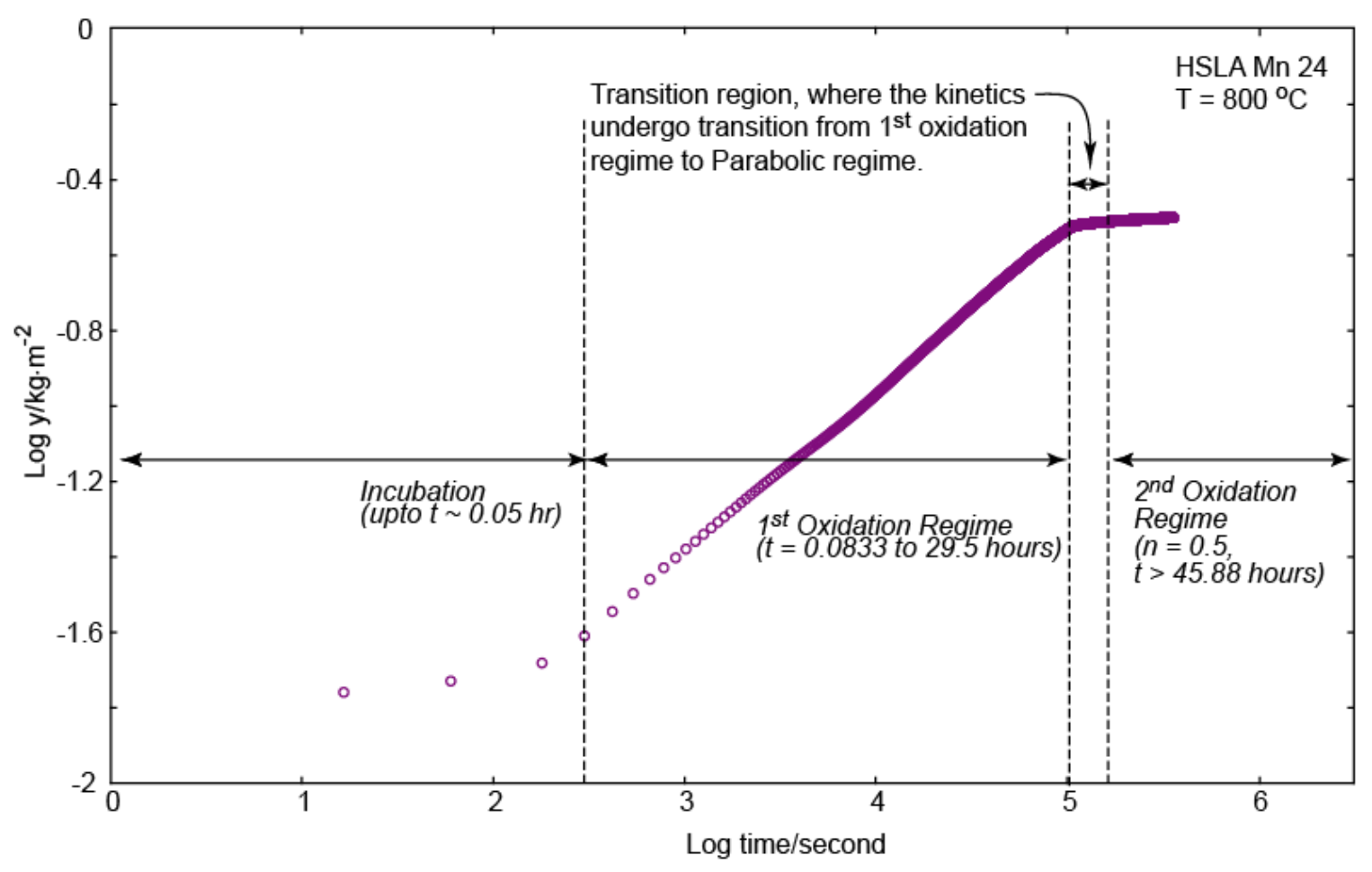

Figure 3. Log-Log plot of weight gain per unit surface area versus time for Mn-24 at $800{ }^{\circ} \mathrm{C}$ showing the different oxidation regimes. 


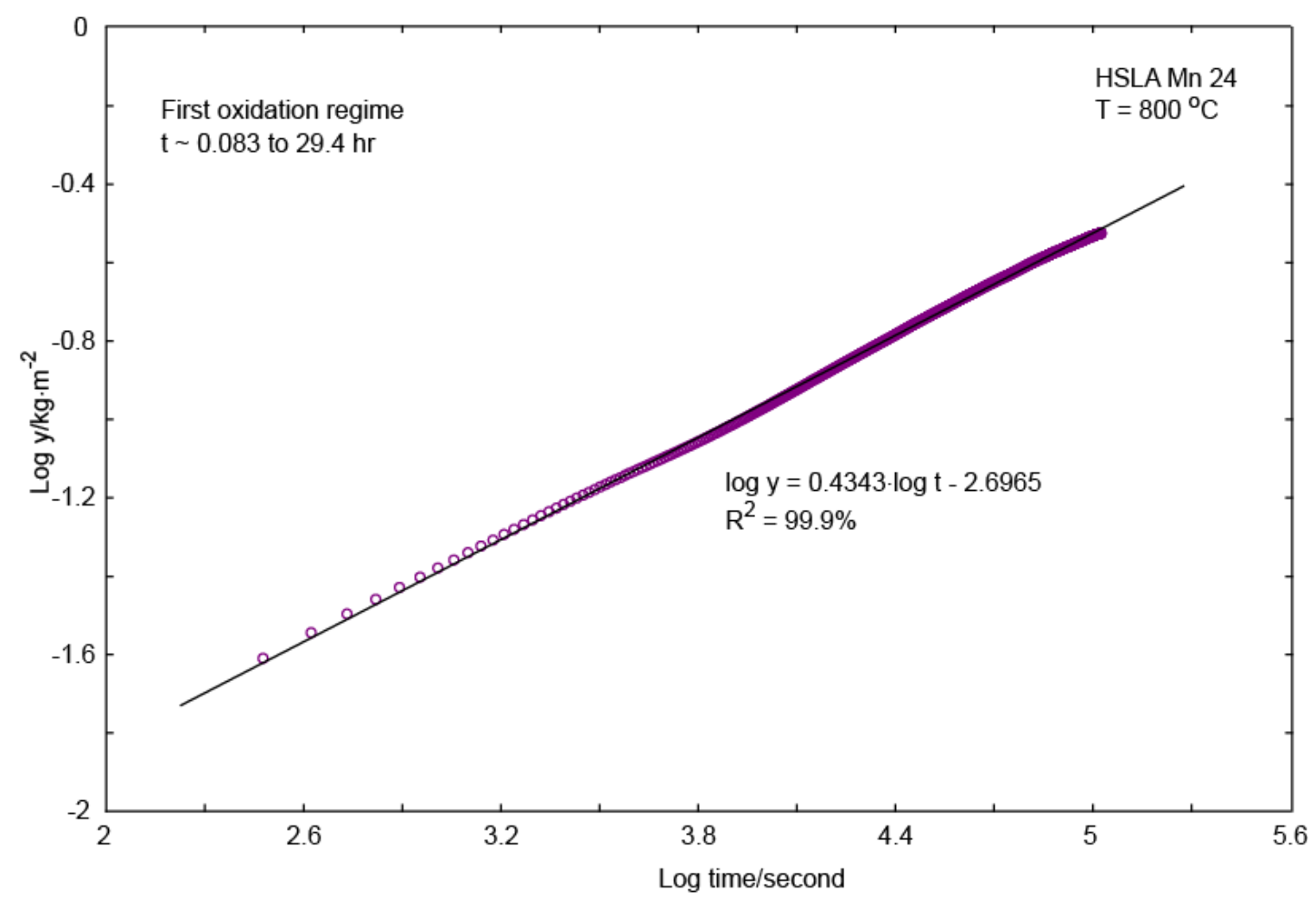

Figure 4. Kinetic parameters for $\mathrm{Mn}-24$ at $800{ }^{\circ} \mathrm{C}$ for the first oxidation regime ( $\mathrm{t}=0.083$ to $29.4 \mathrm{hr}$ ). 


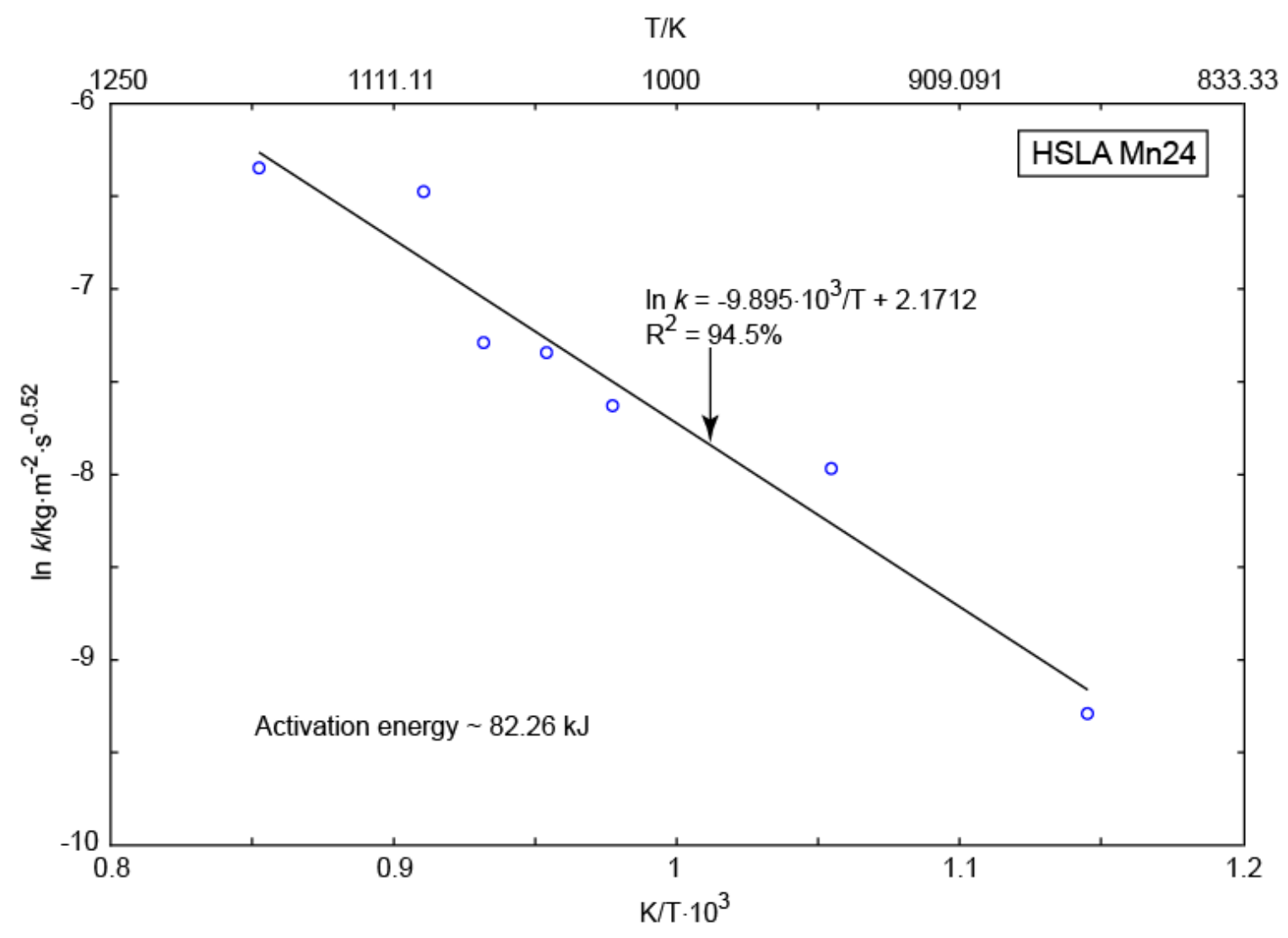


Figure 5. Activation energy for Mn-24 for the first oxidation regime is calculated from a plot of $\mathrm{ln}$ $\mathrm{k}\left(\mathrm{kg} \cdot \mathrm{m}^{-2} \cdot \mathrm{s}^{-0.52}\right)$ versus $1 / \mathrm{T}(K)$. The time exponent of rate law has been assumed to be 0.52 to maintain consistency of units.

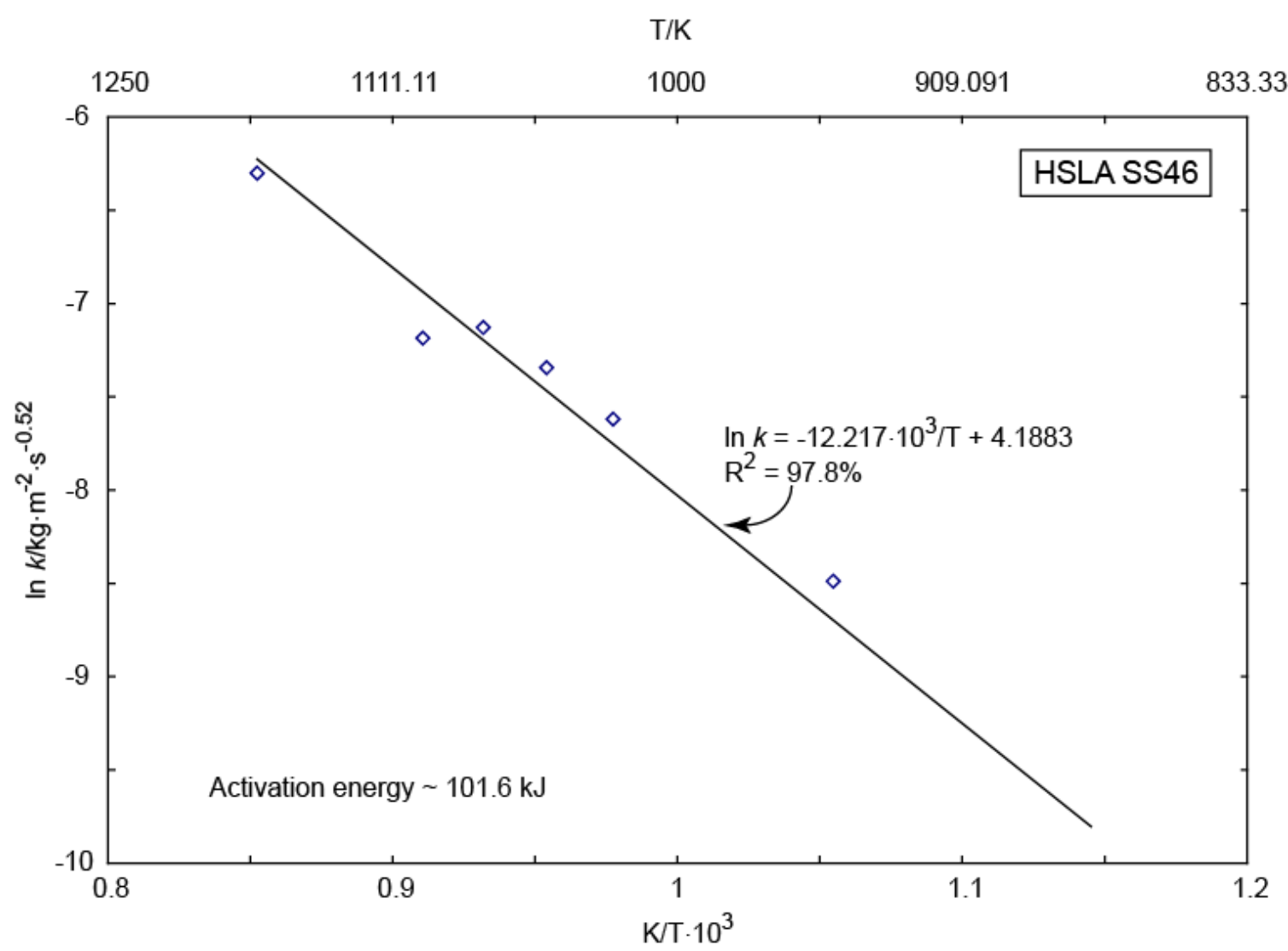


Figure 6. A $\ln \mathrm{k}\left(\mathrm{kg} \cdot \mathrm{m}^{-2} \cdot \mathrm{s}^{-0.52}\right)$ versus $1 / \mathrm{T}(K)$ plot for calculation of Activation energy for SS-46 for the first oxidation regime. The time exponent of rate law has been assumed to be 0.52 to maintain consistency of units.

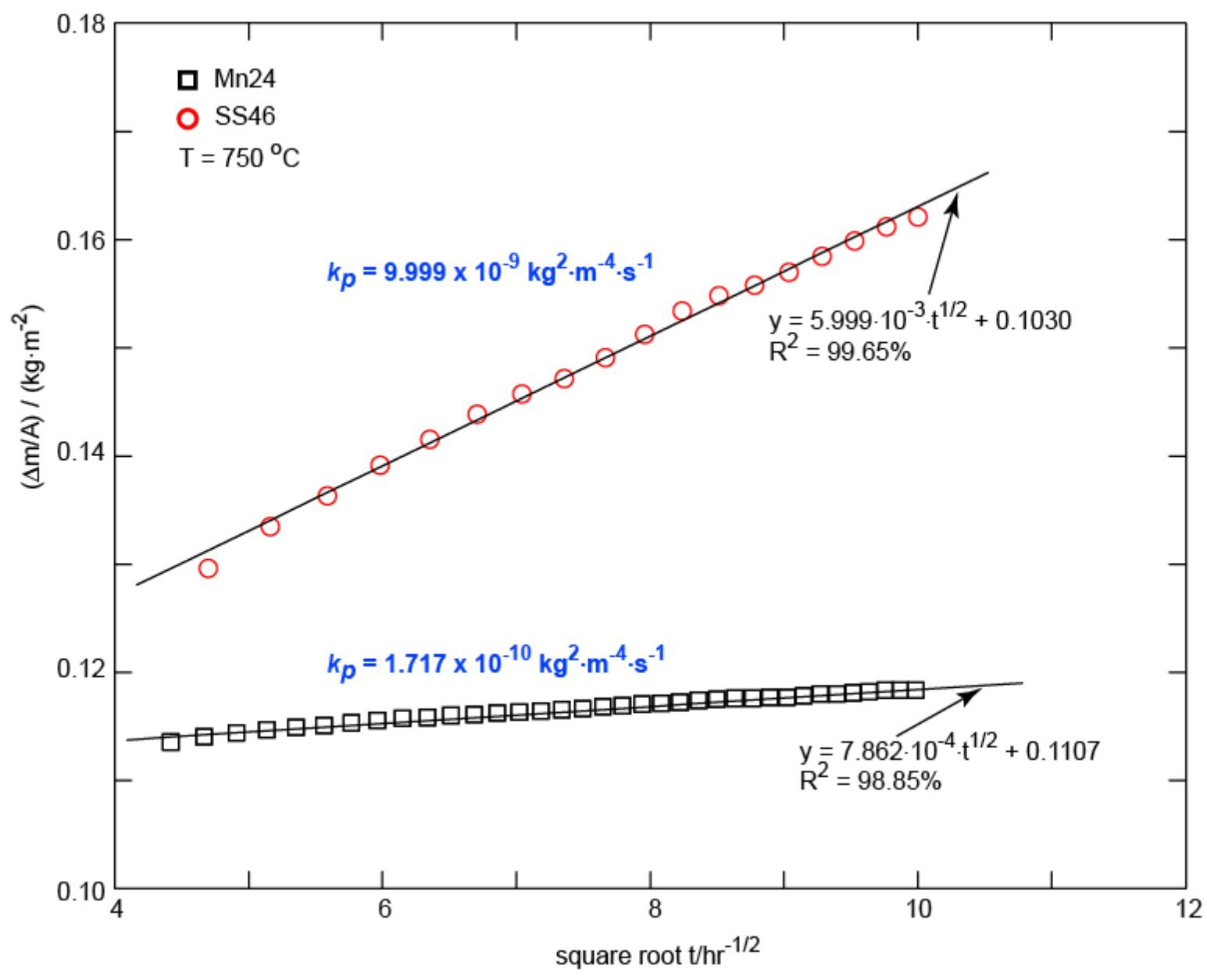


Figure 7. A plot of $y$ versus root $t$ for SS46 and Mn24 to show the long term parabolic oxidation behaviour at $750{ }^{\circ} \mathrm{C}$. The parabolic rate constant of Swellex Mn24 is an order of magnitude lower than SS46.
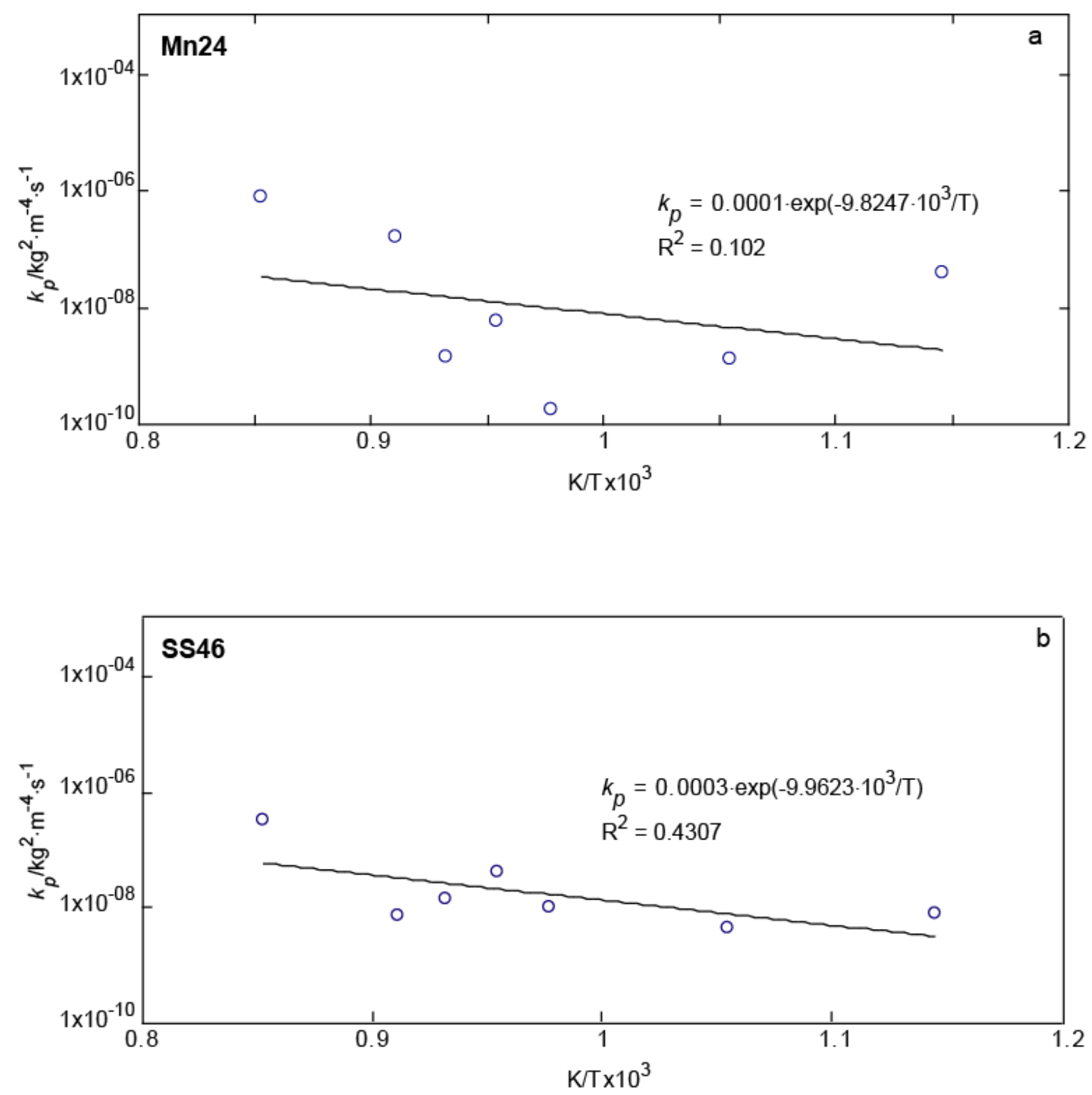
Figure 8. A plot of $\ln k_{p}\left(\mathrm{~kg} \cdot \mathrm{m}^{-2} \cdot \mathrm{s}^{-1}\right)$ versus $1 / \mathrm{T}(\mathrm{K})$ to determine the activation energy for (a) Mn-24 and (b) SS-46 for the second oxidation regime. Scatter in temperature dependence of the parabolic constants on the Arrhenius plot is attributed to oxide-scale failure and the formation of different oxides [39].
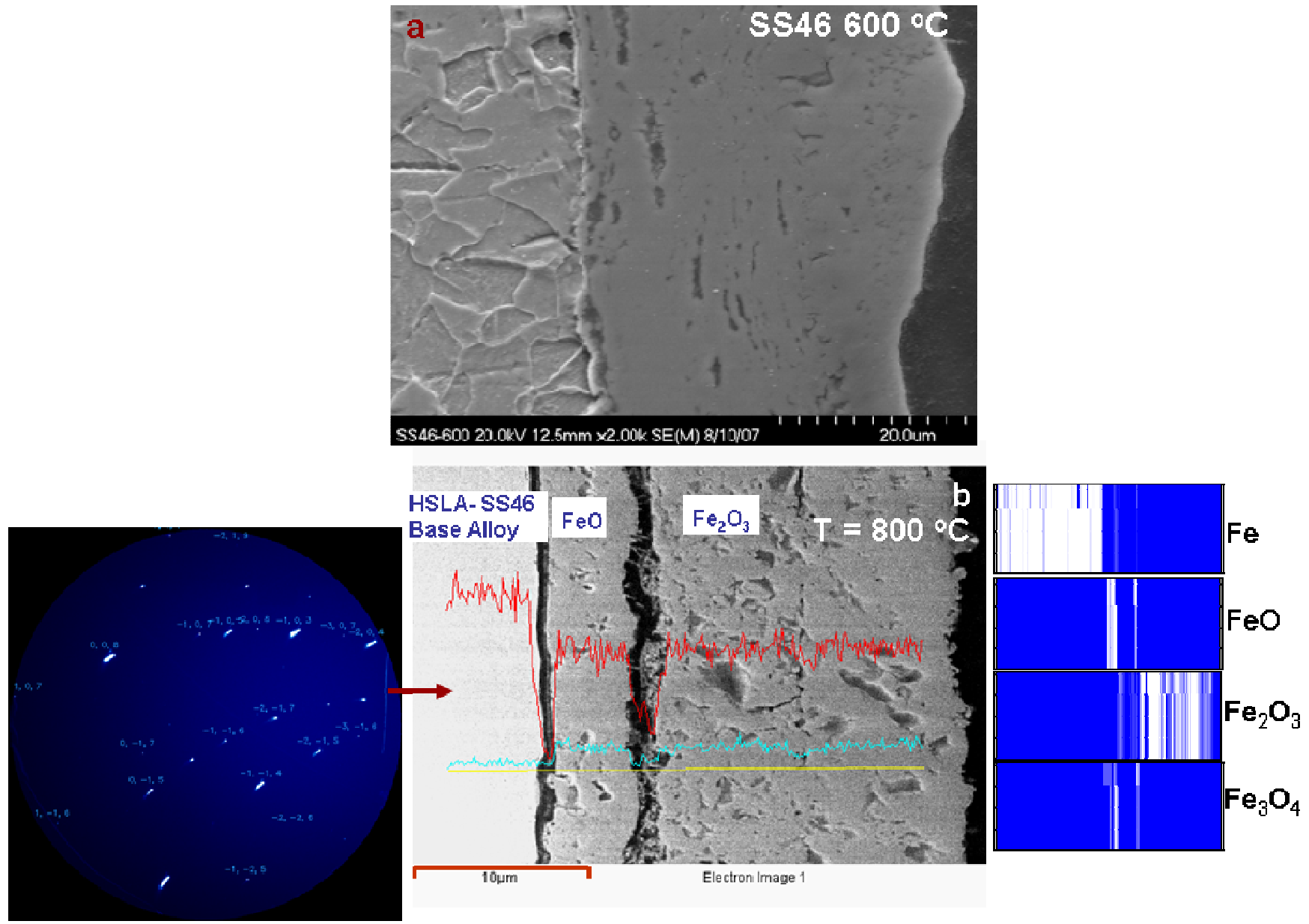

Magnetite? 
Figure 9. Oxide layer on SS46 (a) after 100 hours of oxidation at $600{ }^{\circ} \mathrm{C}$ under pure oxygen. (b) Three distinct layers in the oxide scale observed after $100 \mathrm{hr}$ oxidation at $800{ }^{\circ} \mathrm{C}$. L to R: Wustite, possibly magnetite and hematite layers are identified based on the EDAX results and validated by synchrotron microdiffraction.

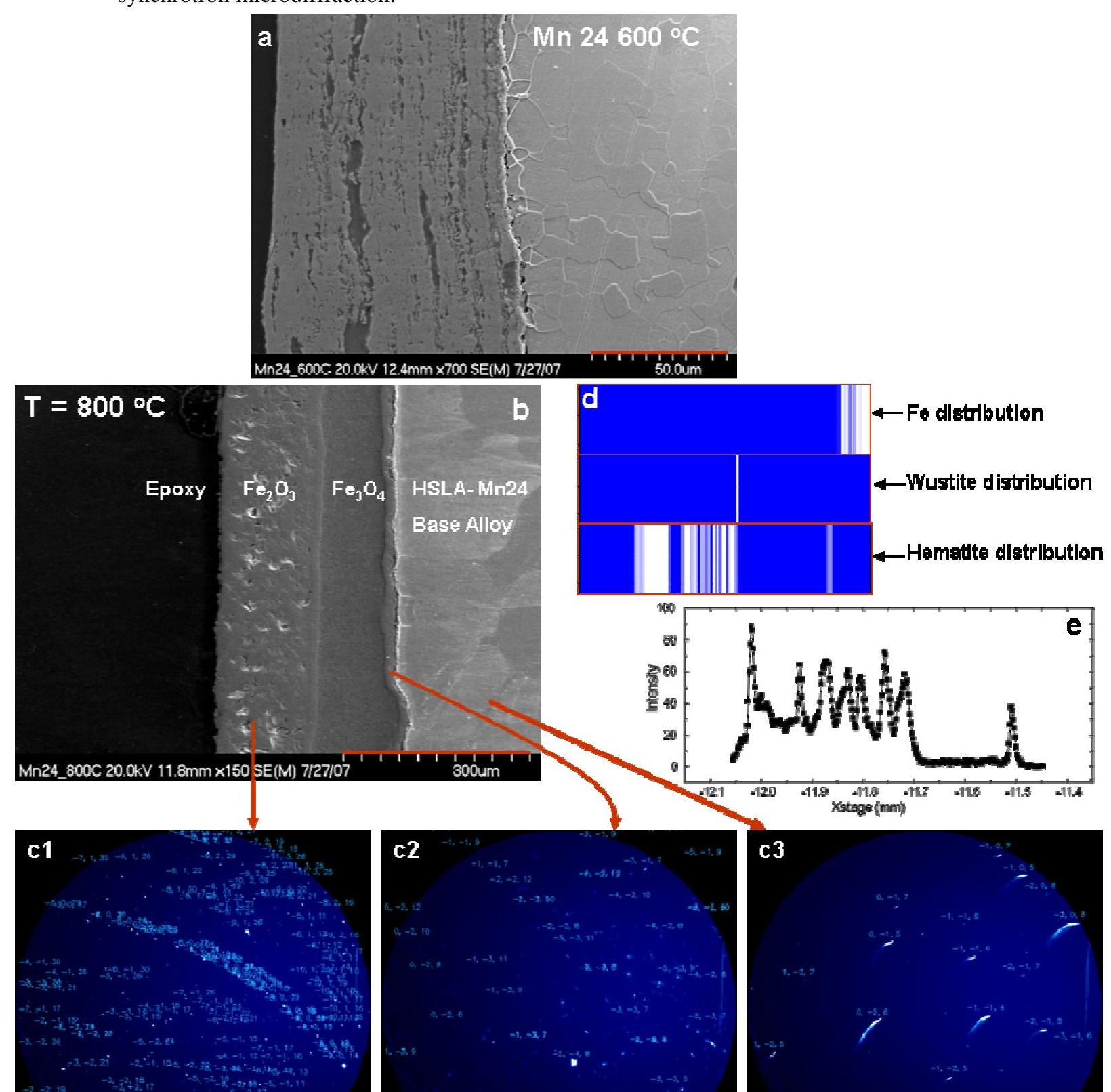


Figure 10. Oxide layer on Mn24 (a) after 100 hours of oxidation at $600{ }^{\circ} \mathrm{C}$ under pure oxygen. Oxide layer separation is observed at the steel-scale interface (b) three distinct layers in the oxide scale observed after $100 \mathrm{hr}$ oxidation at $800{ }^{\circ} \mathrm{C}$. Synchrotron microdiffraction confirmed the presence of hematite, magnetite and wustite layers from L to R. The scale formed on this alloy is thicker than SS46.

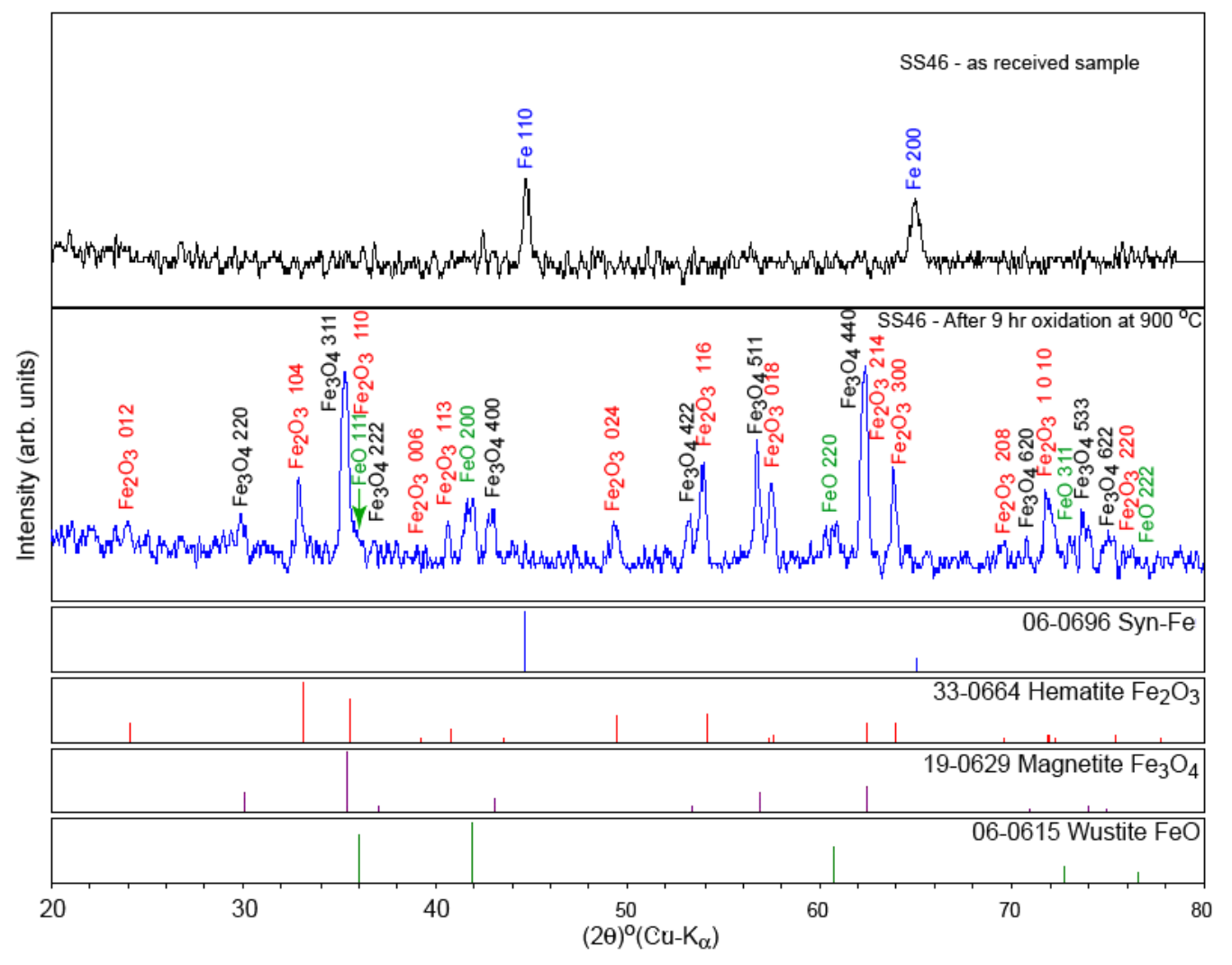


Figure 11. X-ray Diffraction Pattern of as-received SS46 sample and after oxidation at $900{ }^{\circ} \mathrm{C}$. The oxidized sample shows predominantly hematite and magnetite with noticeable amounts of wustite.

Table 1. Chemical analyses of the Rockbolt used in this study ${ }^{\mathrm{a}}$

\begin{tabular}{|c|c|c|c|c|c|c|c|c|c|c|c|c|}
\hline Alloy & $\mathrm{Ni}$ & $\mathrm{Cr}$ & Mo & $\mathrm{Si}$ & $\mathrm{Mn}$ & $\mathrm{C}$ & $P$ & $\mathrm{~S}$ & $\mathrm{~V}$ & & & \\
\hline $\begin{array}{l}\text { SS46 (ASTM A607- } \\
\text { 98, Grade 50) }\end{array}$ & 0.06 & 0.02 & 0.03 & - & 0.68 & 0.07 & 0.01 & 0.01 & $\begin{array}{l}\mathrm{V} \\
0.038\end{array}$ & $\begin{array}{l}\mathrm{Cb} / \mathrm{Nb} \\
0.007\end{array}$ & $\begin{array}{l}\mathrm{Cu}+\mathrm{Ni}- \\
\mathrm{Cr}+\mathrm{Mo}\end{array}$ & 0.22 \\
\hline Swellex Mn24 & 0.05 & 0.042 & 0.027 & 0.24 & 1.16 & 0.16 & 0.013 & 0.004 & $\begin{array}{l}\mathrm{Al} \\
0.054\end{array}$ & $\begin{array}{l}\mathrm{Cu} \\
0.17\end{array}$ & $\mathrm{~N}$ & 0.006 \\
\hline $\mathrm{ST} 2^{\mathrm{b}}$ & 0.26 & - & - & 0.27 & 0.77 & 0.11 & 0.023 & 0.019 & $\begin{array}{l}\mathrm{V} \\
\text { Trace }\end{array}$ & $\mathrm{Ce} \quad 0.78$ & $\mathrm{Ti}$ & 0.046 \\
\hline
\end{tabular}

${ }^{\mathrm{a} B a l a n c e ~ F e . ~}$

${ }^{\mathrm{b}}$ The high strength structural steel with better oxidation resistance reported by Chang [30]. 
Table 2. Rate constant $(k)$ and order of reaction $(n)$ for the first oxidation regime 


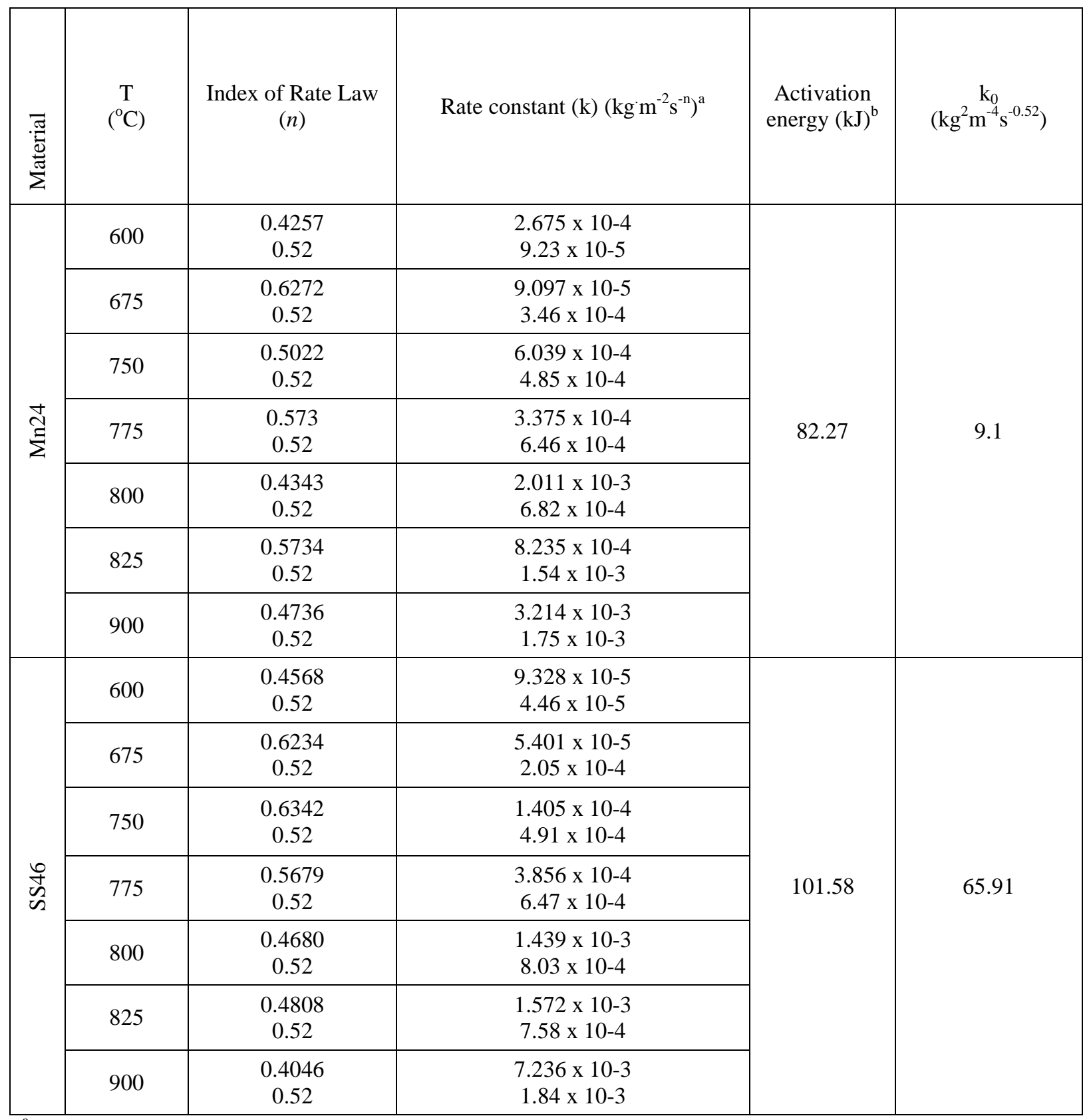

${ }^{a}$ The units of the rate constant will change according to the index of rate law $(n)$.

${ }^{\mathrm{b}}$ Since the index of rate law is actually different for the two temperatures (hence different units of $k$ ), to determine activation energy the index was assumed to be $n=0.52$ for consistent units while plotting $\ln k$ versus $1 / T$. 